\title{
Thai Student Teacher Learning Innovation: A Second-Order Confirmatory Factor Analysis
}

\author{
Achah Binheem, Paitoon Pimdee, Sirirat Petsangsri
}

\author{
King Mongkut's Institute of Technology Ladkrabang, Bangkok, Thailand
}

\begin{abstract}
The study's objective was to analyze the corroborating elements of a Thai student teacher's (TST) learning innovation as perceived through the expertise of their teachers. Therefore, from 12 Thai teaching universities (Rajabhats) located across four Thai regions, multiple sampling techniques were used to select a sample of 151 teaching professionals. The research instrument was a questionnaire using a 5-level scale to assess the opinions on the four latent and 12 observed variables. The results showed that of the three latent variables analyzed that contributed to TST learning innovation (IN), learning innovation use (US) were perceived as most important, followed by the learning innovation development process (DE) and then the TST's creative collaboration (CO) abilities, respectively. Finally, all the observed variables were determined to be compatible with TST innovation learning at a 'high' level.
\end{abstract}

Keywords - creative collaboration, learning innovation use, pre-service teachers, Rajabhat universities, Thailand.

\section{Introduction}

Nowadays, technological advances and knowledge transitions are fast and endless, so teachers need to

DOI: $10.18421 /$ TEM104-48

https://doi.org/10.18421/TEM104-48

Corresponding author: Achah Binheem,

School of Industrial Education and Technology, King Mongkut's Institute of Technology Ladkrabang, Bangkok, Thailand.

Email: achah.b@pkru.ac.th

Received: 03 July 2021.

Revised: 25 October 2021.

Accepted: 02 November 2021.

Published: 26 November 2021.

(c) BY-NC-ND(C) 2021 Achah Binheem, Paitoon Pimdee \& Sirirat Petsangsri; published by UIKTEN. This work is licensed under the Creative Commons AttributionNonCommercial-NoDerivs 4.0 License.

The article is published with Open Access at www.temjournal.com develop themselves to enter the new world of learning. It has also been added that $21^{\text {st }}$ century generation $Z$ students expect and use the ICT and social media like fish do to water [1]. Additionally, pre-service teachers/student teachers and their respective universities should be technically savvy and properly outfitted if they expect to engage this newer generation of students effectively. Therefore, teaching innovation requires adjusting the teaching and learning process by changing learners' behavior and applying modern technology as a tool to stimulate learners' learning.

These ideas are also consistent with the implementation of Thailand 4.0 goals, which details that a creative society requires innovation and that success requires different thinking and skills from both students and educators [2]. Also, Thailand 4.0 emphasizes technological innovation and education, digital entrepreneur assistance, enabling greater internet access, and retraining older generation factory workers to new knowledge workers [3].

Moreover, there is a need for public-privatecommunity engagement, new technologies, and learning networks. Furthermore, the Thai Ministry of Education (MOE) has set goals within the national education plan to develop learners to have problemsolving skills, innovational attributes, and creative thinking learning skills required for a 21 st century knowledge worker [4], [5], [6].

Therefore, as we can see from the above, the concept of knowledge creation and innovation goes hand-in-hand, as innovation is the creation of new things, new methods, and education in which learners need to think of new things and new processes [7]. Also, educational innovation should be focused on the teaching and student learning of innovation theory and practice [8]. These ideas are consistent with other research from Thailand in which school administrators were stated as having the critical responsibility in creating innovation within their schools [9].

Therefore, to be an academic leader and meet the needs of agencies or organizations in the 21st century, educators must embrace innovation or knowledge creation. Furthermore, in the Nonaka and 
Takeuchi Model, innovation is a multistep process that depends on each scholar analyzing and drawing conclusions according to the context of the environment in which that step is applied [10]. Therefore, the exchange of knowledge, opinions, and experiences must be accomplished [11], [12], [13], [14], [15].

From the preceding, the authors saw that promoting the creation of learning innovation for teaching students will strengthen professional teachers and their student teachers. Therefore, teachers must engage in innovation and creative initiatives to create innovations to solve problems related to teaching and learning management. In particular, educators must elevate the quality of education of student teachers and bring their education in line with the 21st-century skills standards [15]. Finally, from the use of second-order confirmatory factor analysis, it is hoped that the variables identified for innovation can be confirmed and validated.

\section{Brief Literature Review}

\subsection{Learning Innovation Process Development (DE)}

Much has been written concerning the Japanese use of innovation on process development within the Japanese automotive sector. One early visionary concerning the process of continuous innovation was Nonaka, who is famously quoted as saying that "the only certainty is uncertainty" and that knowledge is the key to lasting competitive advantage [16, p.96]. Therefore, under conditions of rapid change, organizations must not focus on their core because the core can quickly disappear. Therefore, the edge represents an opportunity for organizations to target innovation in emerging markets [17].

Similarly, educational innovation enhances 21st century skills for higher education learners, with the learning process requiring both creativity and innovation [15]. Therefore, creativity and innovation can be transferred to other disciplines and outside work environments [18].

\subsection{Creative Collaboration (CO)}

According to Wolff, a significant trend now in $\mathrm{CO}$ is flattening hierarchies, both inside and across organizations [19]. Also, educational collaboration accelerates, mainly when schools are scattered, through technology, social tools, and digital platforms. Additionally, the ICT (information, communications, and technology) collaboration amongst groups catalyzes creativity, facilitating multidisciplinary innovation while reducing barriers and inefficiencies to individuals who work together [20]. Finally, innovation requires the collaboration of ideas and value creation [17], with value creation necessitating bringing new ideas to market that ultimately creates value from studying, analyzing, and synthesizing theories about the components of innovation.

\subsection{Learning Innovation Use (US)}

It is hard to discuss innovation in learning and not discuss technology in an almost limitless variety and forms. Today, under the mandated global lockdowns due to the Covid 19 pandemic, online learning has moved to the forefront of learning innovation. Online learning can save time, cost and increase education's efficiency [8]. At the same time, other scholars talk about the use of flipped classrooms and blended learning as innovative use of technology and the creation of student creativity, critical thinking, and motivation. Various studies have also pointed out how well and quickly student-teachers can adopt YouTube material in a flipped classroom model [21].

Moreover, digital devices in flipped classrooms now allow access to lessons and teachers at any time from anywhere. This allows students to choose how, where and when they learn [22], [23].

Therefore, as we can see, learning innovation use is a powerful vehicle in delivering cutting-edge lessons to a curious and motivated study body. The only limiting factors beyond the unwillingness of teachers and administrators to adopt new ideas and methods are the reliability of the technology, its access, and its cost.

\subsection{Research Objectives}

1) To analyze and confirm the factors affecting Thai student-teacher learning innovation creation.

2) To verify the coherence of the learning innovation component measurement model with the empirical data.

\section{Materials and Methods}

\subsection{Population and Sample}

The study's population was professors and lecturers teaching in the Computer Studies, Sciences, and Mathematics Departments in one of 12 Thai teaching and education Rajabhat Universities' Faculties of Education. In the 2019 academic year second semester, this number was 238 individuals for the 12 institutions targeted.

From this population, the researchers noted numerous methods in which a reliable sample size can be obtained. Therefore, the sample size method 
was based on the proportion between the sample units and the number of variables observed in the research. Using this method, studies have suggested that a ratio of 10:1 is sufficient in confirmatory factor analysis (CFA) research [24].

As there were 12 observed variables, the minimum sample size was calculated as 120 individuals, which was increased to 151 students to strengthen the model in testing the CFA with a higher correlation. Afterward, the student survey selection process used multistage random sampling in which schools from four separate Thai regions were selected (Table 1.). Subsequently, stratified random sampling (SRS) was employed to randomly select Rajabhat universities across the country according to the proportion of each geographic region, from which a total of 12 universities were sampled. After that, SRS was employed again to randomly select the disciplines obtained from the first stage's three fields functioning under each region's Rajabhat University Faculty of Education's (1) Computer Education Department, (2) Science Program, and Mathematics Department.

Table 1. Population and sample component of Thai student teachers classified by region and university

\begin{tabular}{|l|c|c|}
\hline \multicolumn{1}{|c|}{ Universities } & Pop. & Sam. \\
\hline Northern Thailand & $\mathbf{1 6}$ & 10 \\
Kamphaengphet Rajabhat University & $\mathbf{1 4}$ & 10 \\
Nakhon Sawan Rajabhat University & & \\
\hline Thailand Central & 20 & 14 \\
Dhonburi Rajabhat University & 17 & 12 \\
Bansomdejchaopraya Rajabhat & $\mathbf{3 4}$ & 12 \\
University & $\mathbf{1 5}$ & 13 \\
Nakhon Pathom Rajabhat University \\
Muban Chombueng Rajabhat University & & \\
\hline Northeast Thailand & $\mathbf{1 6}$ & 11 \\
Chaiyaphum Rajabhat University & $\mathbf{2 8}$ & 9 \\
Nakhon Ratchasima Rajabhat University & $\mathbf{1 6}$ & 12 \\
Sisaket Rajabhat University & $\mathbf{2 3}$ & 19 \\
Rajabhat Maha Sarakham University & & \\
\hline Southern Thailand & 19 & 12 \\
Nakhon Si Thammarat Rajabhat & $\mathbf{2 0}$ & 17 \\
University & & \\
Phuket Rajabhat University & 238 & 151 \\
\hline \multicolumn{1}{|c|}{ Totals } &
\end{tabular}

Note. Pop. $=$ population, Sam. $=$ sample component

\subsection{Research Tools}

The data collection tool used a two-part questionnaire on student-teacher learning innovation creation based on the opinions of their professors and lecturers.

In part 1, the questionnaire contained general information concerning gender, educational level, academic position, and work experience, which was in the form of a checklist.

In part 2, the questionnaire was divided into three sections concerning the learning innovation development process (DE), creative collaboration
(CO), and learning innovation use (US). Each item was ranked according to a five-level agreement scale from $1-5$ (Table 2.).

\subsection{Research Instrument Creation and Quality and Reliability Assessment}

Initially, the authors undertook an analysis of the literature and defined the initial questions for inquiry and subsequent analysis. We then proceeded to create and improve items for later inquiry by the targeted sample group. During this process, a five-level Likert agreement questionnaire was developed in which a value of $1(1.00-1.49)$ expressed 'strong disagreement, a value of $2(1.50-2.49)$ expressed 'minimal agreement,' a value of $3(2.50-3.49)$, a value of $4(3.50-4.49)$, and finally, a value of 5 $(4.50-5.00)$ expressed the most agreement with the item's statement [25].

After the questionnaire's development, five experts were asked to review each item and assess the survey instrument's content validity. As it is accepted practice, an Item Objective Congruence (IOC) Index is assigned by the experts and then calculated and evaluated by the researchers as criteria $(\mathrm{IOC} \geq .50)$ for judging each item's quality. Results from this process returned values from $0.60-1.00$, thus assuring the questionnaire's quality.

Another common technique used in assuring questionnaire reliability is the 'pilot test.' As such, the researchers selected 30 students who did not participate in the study's final survey to assess the questionnaire items. Using the Cronbach $\alpha$ values suggested by George and Mallery $(\alpha \geq .9$ is excellent) [26], pilot test results revealed an overall item $\alpha$ average of 0.96 (excellent).

\subsection{Ethics Clearance}

Before the study's commencement, the researchers sought and obtained ethics approval from their university's Human Ethics Committee before discussions with the initial group of five education experts relating to the survey's design and assessment. After that, before questionnaire distribution to the pilot-test group and the following sample group, all individuals were made aware of the confidential nature of their data.

\subsection{Data Collection}

Beginning in March 2021 through the end of April 2021, the researchers and their graduate assistants collected data from teaching professionals at one of 12 Thai Rajabhat teaching universities scattered throughout four Thai regions.

Moreover, from the use of the initial multistage sampling and subsequent stratified random sampling, three separate departments working under each university's Faculty of Education were targeted. These departments and their instructors were from the Computer Education Departments and the Science and Mathematics Departments. 
Due to COVID-19 pandemic access issues and onagain/off-again lockdowns, we coordinated the distribution and collection of our questionnaires through a network of faculty members in each university's department.

The result was the successful and complete acquisition of 151 questionnaires, with the sample size being supported by related theory [24].

\subsection{Data Analysis}

Data were analyzed using two different statistical analysis software packages, with the descriptive statistics analysis (e.g., mean, SD, skewness, kurtosis) being undertaken by use of IBM ${ }^{\circledR}$ SPSS $^{\circledR}$ for Windows Version 25. LISREL 8.72 was used for the final second-order CFA modeling.

\section{Results}

\subsection{Second-Order CFA results}

In Table 2., all the observed variables were determined to be compatible with Thai studentteacher (TST) innovation learning at a 'high' (3.50 4.49) level (most agreement).

Table 2. Latent and observed variable mean and SD

\begin{tabular}{|c|c|c|c|}
\hline Latent and Observed Variables & Item & $\bar{x}$ & SD. \\
\hline $\begin{array}{l}\text { Learning innovation development } \\
\text { process }\end{array}$ & $\mathbf{D E}$ & 4.22 & .57 \\
\hline $\begin{array}{l}\text { 1. I think TSTs should be able to set } \\
\text { goals consistent with the problem of } \\
\text { creating innovative learning. }\end{array}$ & b1 & 4.29 & .71 \\
\hline $\begin{array}{l}\text { 2. I think TSTs should be able to } \\
\text { design innovative learning based on } \\
\text { established principles and theories. }\end{array}$ & b2 & 4.26 & .70 \\
\hline $\begin{array}{l}\text { 3. I think TSTs should be able to } \\
\text { create innovation in learning according } \\
\text { to established goals. }\end{array}$ & b3 & 4.13 & .75 \\
\hline $\begin{array}{l}\text { 4. I think TSTs should be able to } \\
\text { experiment and improve the } \\
\text { educational environment through } \\
\text { learning innovation. }\end{array}$ & b4 & 4.25 & .70 \\
\hline $\begin{array}{l}\text { 5. I think it is essential that TSTs } \\
\text { should be able to present/distribute } \\
\text { their concepts for learning innovations } \\
\text { to parents and the public. }\end{array}$ & b5 & 4.18 & .66 \\
\hline Creative collaboration & $\mathrm{CO}$ & 4.34 & .56 \\
\hline $\begin{array}{l}\text { 6. I think it is essential that TSTs } \\
\text { should be able to express their } \\
\text { thoughts to others effectively. }\end{array}$ & b6 & 4.28 & .67 \\
\hline $\begin{array}{l}\text { 7. I think TSTs should accept and } \\
\text { respect others' opinions in improving } \\
\text { learning through innovation. }\end{array}$ & b7 & 4.44 & .73 \\
\hline
\end{tabular}

\begin{tabular}{|l|c|c|c|}
\hline \multicolumn{1}{|c|}{ Latent and Observed Variables } & Item & $\bar{x}$ & SD. \\
\hline $\begin{array}{l}\text { 8. I think TSTs should be able to } \\
\text { exchange knowledge and ideas to help } \\
\text { achieve goals. }\end{array}$ & b8 & 4.29 & .69 \\
\hline \multicolumn{1}{|c|}{ Learning innovation use } & US & $\mathbf{4 . 2 4}$ & $\mathbf{. 5 8}$ \\
\hline $\begin{array}{l}\text { 9. I think TSTs should be able to solve } \\
\text { problems according to the established } \\
\text { goals and objectives. }\end{array}$ & b9 & 4.22 & .75 \\
\hline $\begin{array}{l}\text { 10. I think TSTs should understand } \\
\text { that the results of learning operations } \\
\text { are operationally feasible (b10). }\end{array}$ & b10 & 4.23 & .64 \\
\hline $\begin{array}{l}\text { 11. I think TSTs should use cost- } \\
\text { effective resources to solve problems } \\
\text { (b11). }\end{array}$ & b11 & 4.21 & .69 \\
\hline $\begin{array}{l}\text { 12. I think established criteria should } \\
\text { measure a TST's effectiveness }\end{array}$ & b12 & 4.29 & .74 \\
\hline
\end{tabular}

Table 3. details the Pearson correlation analysis results for the relationships between the observed variables.

Table 3. Correlation, skewness, and kurtosis of the observed variables

\begin{tabular}{|c|c|c|c|c|c|c|c|c|c|c|c|c|}
\hline Var. & b1 & $\mathbf{b 2}$ & $\mathbf{b 3}$ & $\mathbf{b 4}$ & $\mathbf{b 5}$ & $\mathbf{b 6}$ & $\mathbf{b 7}$ & $\mathbf{b 8}$ & $\mathbf{b 9}$ & $\mathbf{b 1 0}$ & $\mathbf{b 1 1}$ & $\mathbf{b 1 2}$ \\
\hline b1 & $\mathbf{1 . 0 0}$ & & & & & & & & & & & \\
\hline b2 & .57 & $\mathbf{1 . 0 0}$ & & & & & & & & & & \\
\hline b3 & .62 & .51 & $\mathbf{1 . 0 0}$ & & & & & & & & & \\
\hline b4 & .59 & .62 & .55 & $\mathbf{1 . 0 0}$ & & & & & & & & \\
\hline b5 & .61 & .58 & .57 & .59 & $\mathbf{1 . 0 0}$ & & & & & & & \\
\hline b6 & .31 & .43 & .36 & .39 & .39 & $\mathbf{1 . 0 0}$ & & & & & & \\
\hline b7 & .59 & .38 & .53 & .52 & .50 & .39 & $\mathbf{1 . 0 0}$ & & & & & \\
\hline b8 & .54 & .55 & .53 & .58 & .54 & .46 & .57 & $\mathbf{1 . 0 0}$ & & & & \\
\hline b9 & .44 & .56 & .57 & .57 & .53 & .45 & .49 & .53 & $\mathbf{1 . 0 0}$ & & & \\
\hline b10 & .49 & .61 & .49 & .61 & .48 & .41 & .50 & .53 & .48 & $\mathbf{1 . 0 0}$ & & \\
\hline b11 & .56 & .56 & .52 & .53 & .66 & .28 & .49 & .59 & .43 & .61 & $\mathbf{1 . 0 0}$ & \\
\hline b12 & .53 & .59 & .60 & .60 & .62 & .42 & .36 & .44 & .60 & .46 & .57 & $\mathbf{1 . 0 0}$ \\
\hline Skew. & -.84 & -.52 & -.61 & -.73 & -.35 & -.66 & -1.10 & -.57 & -.35 & -.24 & -.26 & -.74 \\
\hline Kurt. & .91 & -.35 & .19 & .61 & -.16 & .45 & .54 & -.24 & -.77 & -.67 & -.68 & .15 \\
\hline
\end{tabular}

**All of the observed variables (Var.) under the bold diagonal had a Sig. $\leq .01$, Skew. = skewness, Kurt. = kurtosis

\subsection{Goodness-of-Fit Analysis}

Table 4. details the criteria index, index, value, and supporting theory for the goodness-of-fit (GOF) assessment.

Table 4. GOF assessment

\begin{tabular}{|c|c|c|}
\hline Index & Criteria & Values \\
\hline$\chi 2$ Chi-square & $p \geq 0.05$ & 0.48 \\
\hline $\begin{array}{c}\chi 2 / \text { df relative } \\
\text { Chi-square }\end{array}$ & $\leq 2.00$ & 0.99 \\
\hline RMSEA & $\leq 0.05$ & 0.00 \\
\hline GFI & $\geq 0.90$ & 0.96 \\
\hline AGFI & $\geq 0.90$ & 0.92 \\
\hline RMR & $\leq 0.05$ & 0.03 \\
\hline SRMR & $\leq 0.05$ & 0.03 \\
\hline NFI & $\geq 0.90$ & 0.98 \\
\hline CFI & $\geq 0.90$ & 0.99 \\
\hline
\end{tabular}


From the final second-order CFA modeling for TST learning innovation (IN), it was determined that the $\chi 2$ was $=37.70$, the $\mathrm{df}$ was $=38$, the $p$-value was $=0.48$, and finally, the RMSEA was $=0.000$ (Figure
1.). In Table 5. are the results from the LISREL 8.72 final analysis for pre-service teacher innovation.

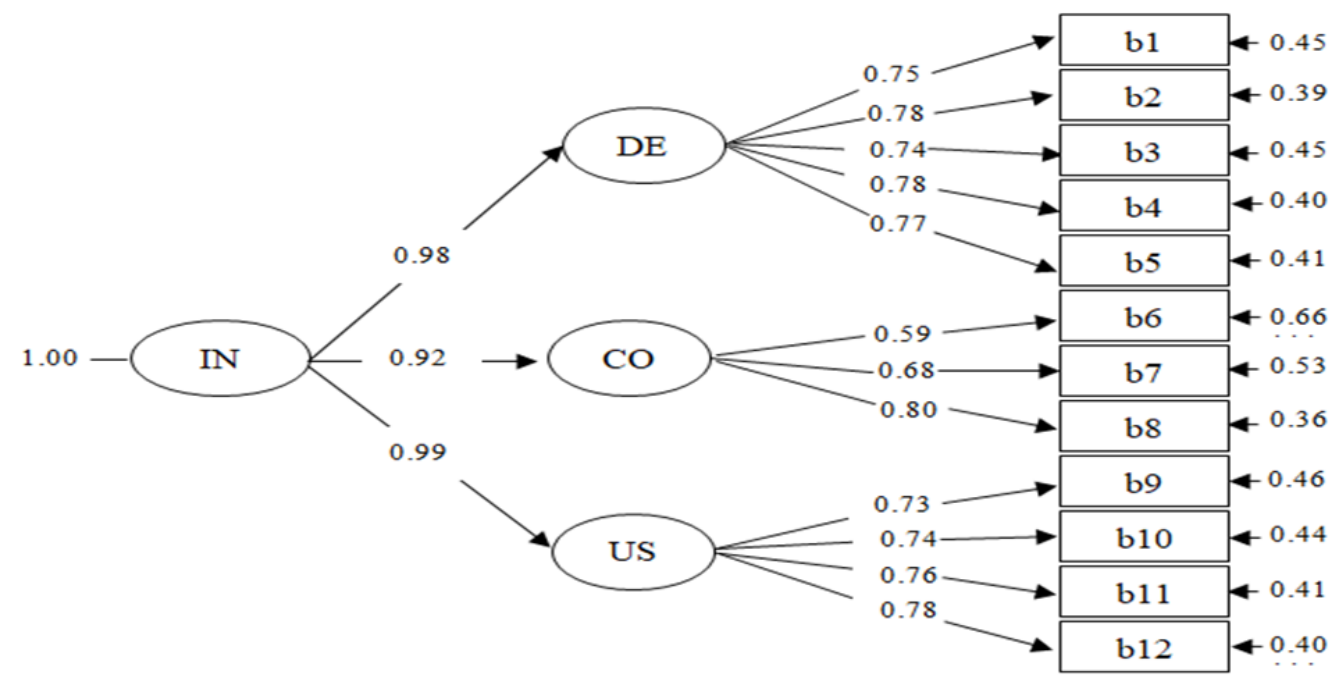

Figure 1. Second-order CFA results for TST innovation importance Source: The authors' LISREL 8.72 analysis Note. $\chi 2=37.70, \mathrm{df}=38, p$-value $=0.48, \mathrm{RMSEA}=0.000$

Table 5. Element weight values of the latent and observed variables and component score coefficients

\begin{tabular}{|c|c|c|c|c|c|c|}
\hline \multirow[t]{2}{*}{ Latent and Observed Variables } & \multicolumn{3}{|c|}{ Variable weights } & \multirow{2}{*}{$\mathbf{R}^{2}$} & \multirow{2}{*}{ CR } & \multirow{2}{*}{ AVE } \\
\hline & $\beta$ & SE & t-test & & & \\
\hline Learning innovation development process (DE) & 0.98 & 0.09 & $10.03 * *$ & 0.97 & 0.88 & $\mathbf{0 . 5 8}$ \\
\hline $\begin{array}{l}\text { 1. I think TSTs should be able to set goals that are consistent with the } \\
\text { problem of creating innovative learning (b1). }\end{array}$ & 0.75 & - & - & 0.56 & & \\
\hline $\begin{array}{l}\text { 2. I think TSTs should be able to design innovative learning based on } \\
\text { established principles and theories (b2). }\end{array}$ & 0.78 & 0.08 & $9.66^{* *}$ & 0.61 & & \\
\hline $\begin{array}{l}\text { 3. I think TSTs should be able to create innovation in learning } \\
\text { according to established goals (b3). }\end{array}$ & 0.74 & 0.08 & $9.70 * *$ & 0.55 & & \\
\hline $\begin{array}{l}\text { 4. I think TSTs should be able to experiment and improve the } \\
\text { educational environment through learning innovation (b4). }\end{array}$ & 0.78 & 0.08 & $9.60 * *$ & 0.60 & & \\
\hline $\begin{array}{l}\text { 5. I think it is important that TSTs should be able to present/distribute } \\
\text { their concepts for learning innovations to parents and the public (b5). }\end{array}$ & 0.77 & 0.08 & $9.47 * *$ & 0.59 & & \\
\hline Creative collaboration (CO) & 0.92 & 0.13 & $7.08 * *$ & 0.85 & 0.74 & 0.49 \\
\hline $\begin{array}{l}\text { 6. I think it is important that TSTs should be able to express their } \\
\text { thoughts to others effectively (b6). }\end{array}$ & 0.59 & - & - & 0.34 & & \\
\hline $\begin{array}{l}\text { 7. I think TSTs should be able to accept and respect others' opinions } \\
\text { in improving learning through innovation (b7). }\end{array}$ & 0.69 & 0.11 & $6.50 * *$ & 0.47 & & \\
\hline $\begin{array}{l}\text { 8. I think TSTs should be able to exchange knowledge and ideas to } \\
\text { help achieve goals (b8). }\end{array}$ & 0.80 & 0.11 & $7.10^{* *}$ & 0.64 & & \\
\hline Learning innovation use (US) & 0.99 & 0.99 & $9.95 * *$ & 0.98 & 0.84 & 0.58 \\
\hline $\begin{array}{l}\text { 9. I think TSTs should be able to solve problems according to the } \\
\text { established goals and objectives (b9). }\end{array}$ & 0.73 & - & - & 0.54 & & \\
\hline $\begin{array}{l}\text { 10. I think TSTs should understand that the results of learning } \\
\text { operations are operationally feasible (b10). }\end{array}$ & 0.74 & 0.08 & $8.93 * *$ & 0.55 & & \\
\hline $\begin{array}{l}\text { 11. I think TSTs should use cost-effective resources to solve problems } \\
\text { (b11). }\end{array}$ & 0.76 & 0.09 & $8.40 * *$ & 0.59 & & \\
\hline $\begin{array}{l}\text { 12. I think TSTs effectiveness should be measured by established } \\
\text { criteria (b12). }\end{array}$ & 0.78 & 0.08 & $9.36^{* *}$ & 0.60 & & \\
\hline
\end{tabular}

$* * p \leq .01, \beta=$ standardized beta coefficient, $\mathrm{SE}=$ standard error, $\mathrm{R}^{2}=$ coefficient of determination, $\mathrm{CR}=$ composite or construct reliability, AVE = average variance extracted 


\section{Discussion}

As suggested by numerous authors, a second-order CFA is a useful tool in assessing a model's construct validity [5]. Therefore, discriminant validity and convergent validity assessment were undertaken to measure the model's construct validity (CV). This is consistent with [27], who also added that a model's $\mathrm{CV}$ is best determined by using a combination of index criteria including the average variance extracted (AVE), the main loadings or correlations, and composite/construct reliability (CR). For further clarification, CR can be interpreted as how the surveyed individuals respond, while the $\mathrm{CV}$ is used as the measurement means. Moreover, supporting theory suggests that $C R$ values should be $\geq 0.6$ and have an AVE value of $\geq 0.4$.

Therefore, having determined which factors are useful in determining the model's reliability and validity, we can see from Table 5. that the latent variable's CR values were $0.74-0.88$, showing strong support for the model's reliability. Also, the study's latent variables AVE were $0.49-0.58$. Therefore, the lower value of 0.49 is acceptable for construct validity as the construct reliability values are all $\geq 0.6$. Therefore, the model's reliability and validity were established, with the results indicating a strong CV.

Also tested in the model's CFA was the coefficient of determination $\left(\mathrm{R}^{2}\right)$, with multiple scholars suggesting that that $R^{2}$ values should not be $\leq 0.20$, with Table 5. showing that the lowest $R^{2}$ was 0.34 for b6. Once again, another criterion was met in establishing the model's acceptability and strength.

Additionally, the study also used a t-test, from which numerous studies have stated that when the absolute $t$-value is $|t| \geq 1.96$, the results are significant. Once again, from Table 5. data we find that the lowest reported t-value for each of the four latent variables and 12 observed variables was 6.50 for $b 7$ which also had a significance level of $p \leq .01$, indicating strong support for the study's CFA model.

Moreover, standard error (SE) values are used to assess and validate the mean value's reliability, with lower SEs indicating that sampling means are a more accurate indication of the actual population mean. Moreover, greater sample sizes will usually result in a lower SE, with the standard deviation usually affected by the sample's size directly.

Finally, Table 5. shows the $\beta$ values between the dependent and independent variables. This is useful when researchers want to compare the strengths in the relationships [28], with $\beta$ larger values indicating a stronger effect.

Also, it is suggested that in CFA models each latent variable has a minimum of three manifest variables, which was done for this investigation.
Furthermore, it has been suggested that the standardized loading values should be a minimum of $\geq .50$, but ideally $\geq .707$ [29]. As our model resulted in the twelve manifest variables having mean values from $4.13-4.44$, these values were significantly exceeded.

Further review of the model's analysis results shows that the Thai teaching professionals felt that the aspect of collaboration concerning the ability of TSTs to exchange knowledge and ideas to help achieve goals (b8) was most important (Table 5.). Secondary to this idea were three aspects (b2, b4, and b12). However, the educators felt student teachers' ability to express their thoughts and opinions clearly (b6) was of the least importance $(\beta=0.59)$.

We can also determine the relationship strength between the observed variables themselves from the Pearson correlation analysis details provided in Table 3. Moreover, often quoted criteria for Pearson's $r$ uses values of $0.50-1$ as strong, $0.30-0.49$ as moderately strong, and $0.10-0.29$ as a weak correlation. Therefore, from Table 3. we find that the overall range between the variables is $0.28-0.66$, with the pair relationship between b11 and b5 being the strongest. However, the other end of the scale shows that the pair relationship between b11 and b6 was the weakest.

The second-order CFA model was also found to be consistent with the empirical due to the results from the data detailed in Table 4.'s GOF analysis [5]. When we look at the LISREL 8.72 analysis results for the skewness and kurtosis values, it is useful to know that [30] suggests that the skewness values should be $\geq|2|$ and kurtosis values $\geq|7|$. Therefore, we find that the skewness values are within the accepted criteria limits with -0.24 to -1.10 . The same is true for the kurtosis results as they are -0.77 to 0.91 .

In Figure 1. and Table 5., we see the strong relationship of the three latent variables to a TST's innovation (IN), with learning innovation use (US) being strongest, followed by the learning innovation development process (DE) and then their creative collaboration (CO) abilities.

This is consistent with [5] who noted that in Thailand an organization's ability for innovation is essential and a prerequisite in the quest for new technologies and their successful utilization. However, in Thailand 'chalk and talk' methods have long been a recognized problem in the adoption of teaching innovation.

Additionally, the Thai government today has placed the responsibility of educating Thai youth as competitively skilled knowledge workers at the core f creating the Kingdom's 4.0 digital economy and 
economic model. Thus, educators are essential at changing education to equip children with 21 stcentury skills. Therefore, innovation and technology use are at the core of all the initiatives [4], [15].

Moreover, schools and teachers must collaborate in changing old ways of teaching. Also, research has reported that collaboration and learning from one's peers are essential to innovation and learning, with a teacher's learning an ongoing work-related process that leads to cognition and/or behavior changes. Finally, student-teacher learning is a continuous and dynamic process that takes place throughout a teacher's career. It is embedded in a wide range of activities and contexts, including classroom, workshops, and professional development courses, as well as conversations with students, parents, and colleague collaboration.

\section{Conclusions}

The researchers opened an investigation into what factors had the greatest impact on pre-service teacher innovation in Thailand as perceived through the eyes of their professors.

From the use of multiple sampling techniques, 151 individuals teaching at 12 Rajabhat (teaching) universities across four Thai geographical regions were eventually identified. After the determination of the questionnaire's reliability and validity, LISREL 8.72 was used to conduct both the goodness-of-fit analysis and a second-order CFA which determined that the model and its variables were consistent with the empirical data and the established criteria and were an overall excellent fit with the model.

Moreover, the results showed that of the three latent variables analyzed that contributed to TST learning innovation (IN), learning innovation use (US), were perceived as most important followed by the learning innovation development process (DE) and then the TST's creative collaboration (CO) abilities, respectively. Finally, all the observed variables were determined to be compatible with TST innovation learning at a 'high' level.

Therefore, the framework can be used to create tools and guide activity design to develop innovative learning for Thai student teachers. In addition, the draft composition was presented to experts to provide recommendations and opinions, thus resulting in components that are consistent with the creation of learning innovation for teaching student teachers.

\section{Acknowledgement}

Research funding for this study was received from the National Research Council of Thailand (NRCT) (2021 fiscal year) and the KMITL Research and Innovation Services (KRIS).

\section{References}

[1]. Boholano, H. (2017). Smart social networking: 21st century teaching and learning skills. Research in Pedagogy, 7(1), 21-29.

[2]. Buasuwan, P. (2018) Rethinking Thai higher education for Thailand 4.0. Asian Education and Development Studies, 7(2), 157 - 173.

[3]. Rauch, E., De Marchi, M., Jitngernmadan, P., \& Martin, F. M. (2021). A descriptive analysis for education and training on Automation 4.0 in Thailand. In Proceedings of the 11th Annual International Conference on Industrial Engineering and Operations Management, Singapore, March (pp. 7-11).

[4]. Partnership for $21^{\text {st }}$ Century Skills. (2020). What potential role for the Global Partnership for Education? Retrieved from:

https://www.globalpartnership.org/content/21stcentury-skills-what-potential-role-global-partnershipeducation [accessed: 10 June 2021].

[5]. Boonkua, A., Tantinakorngul, A., \& Tungkunanan, P. (2019). Innovative Organization of School under The Office of The Basic Education (OBEC): A Second Order Confirmatory Factor Analysis. International Journal of Industrial Education and Technology, 1(1), 67-76.

[6]. Office of the National Economic and Social Development Board. (2016). The twelfth national economic and social development plan (2017-2021).

[7]. Ferrari, A., Cachia, R., \& Punie, Y. (2009). Innovation and creativity in education and training in the EU member states: Fostering creative learning and supporting innovative teaching. JRC Technical Note, 52374, 64.

[8]. Serdyukov, P. (2017). Innovation in education: what works, what doesn't, and what to do about it?. Teaching \& Learning, 10(1), 4-33.

[9]. Masalee, N., Ariratana, W., \& Sirisooksilp, S. (2021). Developing Factors and Indicators of Growth Mindset for School Administrators in Thailand. International Educational Research, 4(1), p61-p61.

[10]. Nonaka, I., \& Takeuchi, H. (1995). The KnowledgeCreating Company: How Japanese Companies Create the Dynamics of Innovation. University of Illinois at Urbana-Champaign's Academy for Entrepreneurial Leadership Historical Research Reference in Entrepreneurship.

[11]. Barker, M., \& Neailey, K. (1999). From individual learning to project team learning and innovation: a structured approach. The Journal of Workplace Learning, 11(2), 60-67.

[12]. Daud, S., Eladwiah, R., Rahim, A., Alimun, R.. (2008). Knowledge creation and innovation in classroom. International Journal of Human and Social Sciences, 3(1), 75-79 
[13]. Li, Y., Wang, J., Li, X., \& Zhao, W. (2007). Design creativity in product innovation. The international journal of advanced manufacturing technology, 33(3), 213-222.

[14]. Marquardt, M. J. (1999). Action learning in action. Transforming problems and people for world-class organizational learning. Palo Alto. Davies-Black Publishing.

[15]. Songkram, N. (2017, October). Virtual smart classroom to enhance 21 st century skills in learning and innovation for higher education learners. In 2017 Tenth international conference on mobile computing and ubiquitous network (ICMU) (pp. 1-4). IEEE.

[16]. Nonaka, I. (1991). The knowledge-creating company. Havard business review

[17]. Kathy, M. C., Lyn, E. H., \& Faith, W. (2009). The Four Key Elements of Innovation: Collaboration, Ideation, Implementation and Value Creation. Federal Reserve Bank of St. Louis.

[18]. Liao, C., Motter, J. L., \& Patton, R. M. (2016). Techsavvy girls: Learning 21st-century skills through STEAM digital artmaking. Art Education, 69(4), 2935.

[19]. Wolff, B. (2018, August 14). The future of work is creative collaboration. Forbes.

[20]. Fedorowicz, J., Laso-Ballesteros, I., \& PadillaMeléndez, A. (2008). Creativity, innovation, and ecollaboration. International Journal of $e$ Collaboration (IJeC), 4(4), 1-10.

[21]. Noonoo, S. (2012). Flipped learning founders set the record straight. The Journal, 6(20), 12.

[22]. Eppard, J., \& Rochdi, A. (2017). A framework for flipped learning. Proceedings of the 13th International Conference on Mobile Learning 2017, 33-40.
[23]. Shih, W. L., \& Tsai, C. Y. (2017). Students' Perception of a Flipped Classroom Approach to Facilitating Online Project-Based Learning in Marketing Research Courses. Australasian Journal of Educational Technology, 33(5), 32-49.

[24]. Schreiber, J. B., Nora, A., Stage, F. K., Barlow, E. A., \& King, J. (2006). Reporting structural equation modeling and confirmatory factor analysis results: A review. The Journal of educational research, 99(6), 323-338.

[25]. Rajaram, K. (2021). Engaging Learners: A Flipped Classroom Approach. Evidence-based Teaching for the 21st Century Classroom and Beyondinnovationdriven Learning Strategies, 21-75.

[26]. George, D., \& Mallery, P. (2010). SPSS for Windows step by step. A simple study guide and reference (10. Bask1). GEN, Boston, MA: Pearson Education, Inc.

[27]. Hair Jr, J. F., Hult, G. T. M., Ringle, C. M., \& Sarstedt, M. (2021). A primer on partial least squares structural equation modeling (PLS-SEM). Sage publications.

[28]. Khaled, W., Lin, J., Han, Z., Zhao, Y., \& Hao, H. (2019). Test for heteroscedasticity in partially linear regression models. Journal of Systems Science and Complexity, 32(4), 1194-1210.

[29]. Carneiro, J., Rocha, A. D., \& Silva, J. F. D. (2009). Proposal of a validation framework for a new measurement model and its application to the export performance construct. BAR-Brazilian Administration Review, 6(4), 331-353.

[30]. West, S. G., Finch, J. F., \& Curran, P. J. (1995). Structural equation models with nonnormal variables: Problems and remedies. In R. H. Hoyle (Ed.), Structural equation modeling: Concepts, issues, and applications (pp. 56 - 75). Sage Publications, Inc. 